\title{
LESSON 100
}

Display 11

PAPER: A5 (148 × $210 \mathrm{~mm})$.

TARGET TIME: 10 minutes.

Type this index page and put in the leader dots.

Letter Writing

Compose Letters
Preface... . IV

The Doom Machine 23

The Age of Mass .. 53

The Gathering Storm. 81

2001 and all that .. 102
Act One... 2 In the beginming 8

Both in Paris 47

A Pastoral Scene 67

war of Minds :. 92

To the end of time...128

Step 1 Keep the style simple, and at first try to keep each letter to three paragraphs.

Step 2 The first paragraph is an introduction. Say which letter you are replying to, e.g., 'In reply to your letter of', or why you are writing if this is the first contact between you, e.g., 'In reply to the advertisement', and so on. Explain who you are.

Step 3 In the second paragraph get down to what your letter is all about. Seek the information you require or say what it is you want.

Step 4 In the third paragraph look to the future. 'I hope to hear from you soon,' and so on, or express some thanks for the help you have been given. This is the signing off paragraph.

Try typing letters of three paragraphs until you feel that you can express yourself on the typewriter as well as you can when you are writing or speaking to a person on the telephone.

When you type letters, choose the best quality paper you can and do not use thin, cheap paper such as Bank paper. Make sure that the envelope is big enough for the size of letter you have.

1. Look up your local evening paper and write an imaginary letter applying for a job advertised in it.

2. Look up a national paper and write a letter asking for some object you have seen advertised in it.

3. Imagine that the firm you work for ordered some goods a month ago and they are urgently needed. Write to the firm you ordered the goods from and ask them where the goods are.

4. The letter you sent in Task 2 has resulted in your receiving goods which are not what you sent for. Write to the supplier seeking redress. 